\title{
EXPERIMENTS ON THE HEUSLER MAGNETIC ALLOYS.
}

\author{
By K. E. Guthe and L. W. Austin.
}

Heusler's discovery ${ }^{1}$ that it is possible to produce from so-called nonmagnetic metals alloys which approach iron in their magnetic properties has naturally aroused widespread interest. The discovery seems to have been accidental, Dr. Heusler's attention having been drawn to the phenomenon by the filings from some manganese alloys adhering to the tool with which he was working. His first observations were made on manganese-tin and manganese-coppertin. While doubtless magnetic, they were but weakly so and until aluminium was tried as one of the components of the alloy no marked advance was made; the combination manganese-aluminium-copper, however, was found to be strongly ferromagnetic and the work was carried on for the most part with this alloy. The main results of the work by Heusler and his associates ${ }^{2}$ were as follows:

(I) The magnetic properties of an alloy containing a given quantity of manganese are most pronounced when the ratio of aluminium to manganese is about one-half by weight-i. e., when one atom of manganese is present for each atom of aluminium. It was also found that the magnetizability increases more than proportionally as the relative amount of manganese and aluminium increases with respect to the other metal of the alloy. Unfortunately the alloys became at the same time extremely hard and brittle, so that with more than 28 per cent of manganese they are unworkable. Accord-

\footnotetext{
${ }^{1}$ Fr. Heusler, W. Starck, and E. Haupt: Verhandlungen der Physikalischen Gesellschaft, 5, p. 219; r903.

${ }^{2}$ Heusler, Starck, and Haupt: Ueber die ferromagnetischen Eigenschaften von Legierungen unmagnetischer Metalle, Marburg, I904.
} 
ing to the hypothesis of the discoverer, the manganese-aluminiumcopper alloy is a solid solution of manganese-aluminium in copper.

(2) The alloys when first cast seem to have their molecules in a condition of unstable equilibrium and their magnetic properties can be much improved by heating them for many hours at a temperature of about $I I O^{\circ} \mathrm{C}$. (The centigrade scale is used throughout this paper).

(3) At a certain temperature varying with the percentage composition between $70^{\circ}$ and $300^{\circ}$ the alloys lose their magnetizability, which generally returns when the temperature is again reduced. It was found in this connection that the presence of impurities, notably lead, reduced this critical temperature in a marked degree. Lead was also found useful in softening the alloys containing a large percentage of manganese, thus allowing the cast specimens to be turned in a lathe.

Tin, arsenic, antimony, and bismuth can be used instead of aluminium but with less favorable results. The highest value of induction observed was $B=6480$ for $H=\mathrm{I} 50$ gausses in a specimen containing 24.I per cent of manganese.

More recently the work on these alloys was taken up at the Reichsanstalt by E. Gumlich, ${ }^{3}$ who undertook a study of the permeability, coercive force, hysteresis loss and Steinmetz's coefficient under different temperature conditions. He found in agreement with the earlier observers that the permeability increased when the specimen was heated for many hours at $\mathrm{IIO}^{\circ}$, but that heating for a long time at $165^{\circ}$ lowered it again. The hysteresis loss was also greater at $165^{\circ}$ than at lower temperatures. Maintaining the specimen at $-190^{\circ}$ for two hours appeared to have no influence on its magnetic properties. In one specimen examined the permeability attained a maximum (for $B=\mathrm{IIOO}$ ) of $\mathrm{I} 2 \mathrm{OO}$, i. e., equal to that of poor cast steel, but, as it fell to 35 for $B=3000$, this high maximum has more theoretical than practical interest. Steinmetz's coefficient was found to differ not materially from that observed in a poor cast steel. The maximum value of $B$ observed was 4540 for $H=\mathrm{I}_{5} \mathrm{I}$ in a specimen containing 23.5 per cent of manganese. An interesting feature observed is a large viscous magnetic after-effect.

${ }^{3}$ Annalen der Physik, 16, p. 535; I905. 
One of the authors ${ }^{4}$ of the present paper, using the specimens belonging to Professor Gumlich, observed a magnetic expansion amounting to one-third of the maximum found in good soft iron. The form of the expansion curve is similar to that of magnetization, and a large after effect in the magnetostriction was noted.

Fleming and Hadfield ${ }^{5}$ have repeated the work of Heusler, Starck, and Haupt, using the alloys in the form of rings instead of bars. Their results agreed in general with those of the German experimenters, but the specimens used by them appear to have been of poorer magnetic quality.

The conclusions drawn by some experimenters, namely, that we have in these alloys entirely unmagnetic metals, and that magnetism is due to certain forms of molecular groupings, and is not an inherent characteristic of the substance-is not the only explanation of the phenomenon. It is true that the addition of manganese destroys the magnetic properties of iron, but it does not necessarily follow from this that manganese is in its nature nonmagnetic. According to G. Jaeger and St. Meyer ${ }^{6}$ the following suggestive series is formed by the molecular magnetism of nickel, cobalt, iron, and manganese:

$$
\begin{array}{lrl}
\text { Nickel } & I_{m} \mathrm{IO}^{6}=2 \times 2.5 \text { c. g. s. units } \\
\text { Cobalt } & \text { " } & =4 \times 2.5 \\
\text { Iron } & \text { " } & =5 \times 2.5 \\
\text { Manganese } & \text { " } & =6 \times 2.5
\end{array}
$$

According to Liebknecht and Wills ${ }^{7}$ the magnetic susceptibilities of certain salts are as follows:

$$
\begin{array}{ll}
\mathrm{Cu}\left(\mathrm{NO}_{3}\right)_{2}=0.00163 & \mathrm{NiSO}_{4}=0.00435 \\
\mathrm{Ni}\left(\mathrm{NO}_{3}\right)_{2}=0.00443 & \mathrm{Cr}_{2}\left(\mathrm{SO}_{4}\right)_{3}=0.00599 \\
\mathrm{Cr}\left(\mathrm{NO}_{3}\right)_{3}=0.00629 & \mathrm{CoSO}_{4}=0.01019 \\
\mathrm{Co}\left(\mathrm{NO}_{3}\right)_{2}=0.01052 & \mathrm{FeSO}_{4}=0.01272 \\
\mathrm{Fe}\left(\mathrm{NO}_{3}\right)_{3}=0.01352 & \mathrm{MnSO}_{4}=0.015 \mathrm{I} 4 \\
\mathrm{Mn}\left(\mathrm{NO}_{3}\right)_{2}=0.01536 & \mathrm{Fe}_{2}\left(\mathrm{SO}_{4}\right)_{3}=0.015 \mathrm{I} 5
\end{array}
$$

\footnotetext{
${ }^{4}$ Austin: Verhandlungen der Deutschen Physikalischen Gesellschaft, 6, p. 2II; 1904.

${ }^{5}$ Proc. Roy. Society, 76, p. 27I; 1905.

${ }^{6}$ Wiener Berichte, 106, pp. 504, 623, I897; 107, p. 5, 1898.

${ }^{7}$ Annal. der Physik. 1, p. I78, 1900.
} 
It appears, then, that manganese can have strong magnetic properties and belongs to the ferromagnetic group, but may, under certain conditions (those usually met with), be in a nonmagnetic state similar to the nonmagnetic modifications of iron. The resemblance between the two is a very close one, but, as already stated, the transformation to the unmagnetic state takes place in these alloys at a much lower temperature than in iron and seems to be more irregular. Take ${ }^{8}$ has shown that on repeated heating this transformation point is considerably raised, especially in alloys containing lead. In one specimen there was at first a slow change from $75^{\circ}$ to $120^{\circ}$ and on heating to $200^{\circ}$ the critical temperature jumped suddenly to $235^{\circ}$. Heusler and Take believe that in some way on repeated heating the lead loses its property of lowering the transformation point. However, the sudden increase to a temperature much higher than that of a lead-free but otherwise chemically identical alloy $\left(120^{\circ} \mathrm{C}\right.$.) can not be explained by this hypothesis. The most interesting result theoretically of 'Take's experiments seems to be that when the alloys are heated considerably higher than to what might be called the first critical point, namely to $520^{\circ}$, a number of the specimens became permanently nonmagnetic; this change being irreversible even at $-185^{\circ}$. Two other specimens, however, acquired at $520^{\circ}$ a higher magnetization, accompanied by a permanent increase in density, while two others were hardly affected by this high temperature.

These interesting results have been quite recently confirmed by Hill. ${ }^{9}$ He succeeded in transforming an alloy which was hardly altered at $500^{\circ}$ into the nonmagnetic modification by still further heating to about $950^{\circ}$. The large decrease in density when the alloys become nonmagnetic was observed by Hill and interesting comparisons are drawn between the phenomena taking place in iron, nickel, and in Heusler's alloy.

The present experiments were undertaken to examine more fully the form of the magnetization curve of different specimens of the alloys, to obtain more data on the connection between the magnetization and magnetostriction which appeared to show such proportionality according to Austin's observations, and also to examine the

${ }^{8}$ E. Take: Verhandlungen der Deutschen Physik. Ges., 7, p. I33, I905.

${ }^{9}$ B. V. Hill: Physical Review, 21, 335, 1905. 
relation between magnetostriction and thermoelectric force, since Bidwell's ${ }^{10}$ recent work on the close connection between magnetostriction of iron and nickel and their change of thermoelectric force in a magnetic field seemed to call for similar experiments on the Heusler alloys. Our investigation, in which we hoped to include a study of the influence of heat treatment on these properties, had unfortunately to be interrupted, due to one of the authors leaving the Bureau. While not as complete as we could wish, the work may nevertheless be of some interest.

The specimens investigated were obtained directly from Dr. Heusler, and are marked by the numbers I to 6; a specimen belonging to Austin and marked No. o, was also included in our experiments. Dr. H. C. P. Weber, of the chemical division of the Bureau, has greatly added to the value of our data by making a very careful analysis of the first six specimens.

Chemical Analysis.

\begin{tabular}{|c|c|c|c|c|c|c|}
\hline Number.......... & I & 2 & 3 & 4 & 5 & 6 \\
\hline Si ............ & $0.08 \%$ & $0.07 \%$ & $0.02 \%$ & $0.16 \%$ & $0.17 \%$ & $0.05 \%$ \\
\hline $\mathrm{Pb} \ldots \ldots \ldots \ldots$ & 0.07 & 0.07 & 0.13 & 2.03 & 3.14 & 3.84 \\
\hline $\mathrm{Cu}$. & 64.49 & 70.14 & 75.83 & 59.43 & 65.22 & 73.68 \\
\hline Mn & 20.39 & 18.03 & 14.66 & 22.60 & 19.76 & 13.73 \\
\hline Al. & 13.25 & 10.03 & 8.64 & 14.50 & 11.13 & 8.33 \\
\hline $\mathrm{Fe} \ldots$ & 1.05 & 0.99 & 0.55 & 1.31 & 0.67 & 0.46 \\
\hline
\end{tabular}

In $\mathrm{I}$ and 2 no carbon could be detected, in 3 there was a trace of phosphorus, in 4 the silicon seemed to be combined chemically with either iron or aluminum, since when dissolved in hydrochloric acid the silicon was set free as a hydride. This reaction was characteristic for this specimen and did not occur with the others. As will be seen, No. 4 shows also a different magnetization curve from the rest, but our experiments were not carried far enough to decide whether this was due to the peculiar chemical constitution or to a heat treatment different from the others. Gumlich has shown how much a virgin piece may change on subsequent heating and it may be pos- 
sible that No. 4 would have been improved magnetically by such treatment.

The seven specimens, which were carefully turned to a uniform diameter, were very hard and brittle, especially No. I, while 4 did not differ much from 2; due to its high percentage of lead. No. 5 was still somewhat softer while 3 and 6 were not difficult to work. No heat treatment was given to any of the specimens.

In order to compare the results on magnetostriction with the modulus of elasticity, after the conclusion of our observations we asked the section of mechanical testing to determine that constant for us. Although this work was done very carefully on a Riehle testing machine, using a Johnson extensometer to measure the expansion, the pieces behaved in a very irregular way, most of them breaking under a rather small load and revealing in several cases flaws, the one in number 4 being as large as 50 per cent of the cross section. While it was apparent that Young's modulus is very large, we are unable to give even an approximate value for it.

The dimensions of the rods were as follows:

\begin{tabular}{|c|c|c|c|c|c|c|c|}
\hline Number........... & o & $\mathbf{I}$ & 2 & 3 & 4 & 5 & 6 \\
\hline Length, $\mathrm{cm} . . .$. & 17.20 & 13.60 & 12.13 & 12.00 & 14.80 & 12.45 & 12.65 \\
\hline Diameter, cm....... & 0.60 & 0.83 & 0.87 & 0.87 & 0.87 & 0.88 & 0.87 \\
\hline
\end{tabular}

MAGNETIZATION CURVES.

In order to be able to carry the magnetizing field to high values a powerful coil, consisting of 4,000 turns of No. I2 wire, of $5 \mathrm{I} \mathrm{cm}$ length and $2 \mathrm{~cm}$ internal diameter was constructed. The field due to a current through this coil was determined at different distances from the ends by means of an exploring coil and was found to be practically constant over a length of about $20 \mathrm{~cm}$ in the center; for this distance the magnetizing field was given by the equation $H=$ IoO $I$ gausses, if $I$ is expressed in amperes. In order to avoid a possible heating effect in the magnetostriction experiments a double walled tube for the circulation of water was fitted inside the coil, but it was found unnecessary to make use of it, since the heating was appreciable only with currents above 5 amperes and even then 
the time lag was large enough to complete the set before the heating became troublesome.

The ballistic method was employed for the magnetization tests. The secondary coils consisting of double silk-covered wires were wound in the case of alloy No. o directly on the rod, in all other cases on a thin brass tube fitting snugly over the bars. The secondary always covered the whole length of the test piece. The ballistic throw was measured by a galvanometer having a period of twelve seconds and calibrated by means of a standard mutual inductance which remained in the circuit throughout the test. The calibration was checked before every set of observations.

The total flux through the secondary is given by the formula:

$$
\phi=(A H+4 \pi I a) n \text { lines }
$$

where $A$ is the cross section of the secondary, $a$ the cross section of the test piece,

$H$ the actual magnetizing field,

$I$ the average intensity of magnetization, $n$ the number of secondary turns.

In our case the field strength is greatly modified by the end effects, for which correction may be made by assuming for the actual field the formula:

$$
H=H^{\prime}-N I \text {. }
$$

where $H^{\prime}$ is the original field as calculated from the current and $N$ a quantity depending on the dimensions of the magnetized rods. Mann ${ }^{11}$ has shown that up to medium magnetization (for iron up to $I=400) N$ is practically a constant ; for higher values $H$ is slightly incorrect but the general form of the curve is not changed and in our comparison of the magnetization curves with the magnetostriction the errors thus introduced are entirely negligible.

Substituting the value of $H$ in the formula for $\phi$ we obtain

$$
\begin{gathered}
\phi=\left\{A H^{\prime}+(4 \pi a-A N) I\right\} n \\
\text { and } I=\frac{\phi n-A H^{\prime}}{4 \pi a-A N}
\end{gathered}
$$


These formulæ were used for the calculation of $I$ in the following, and $B$ was obtained from the well-known relation between $B, H$, and $I$. $N$ was taken from curves constructed on the basis of Mann's values.

The throw of the galvanometer needle was observed on the reversal of the current. It is well known in the case of iron, and has been shown by Gumlich to be true also for the alloys, that the curve will depend to a certain extent upon the steps chosen. Since we were concerned mainly with comparisons only, we tried to make equal steps as far as possible in the different cases. The results are given in the following tables and curves for $B, I$, and $\mu$ plotted in Figs. I

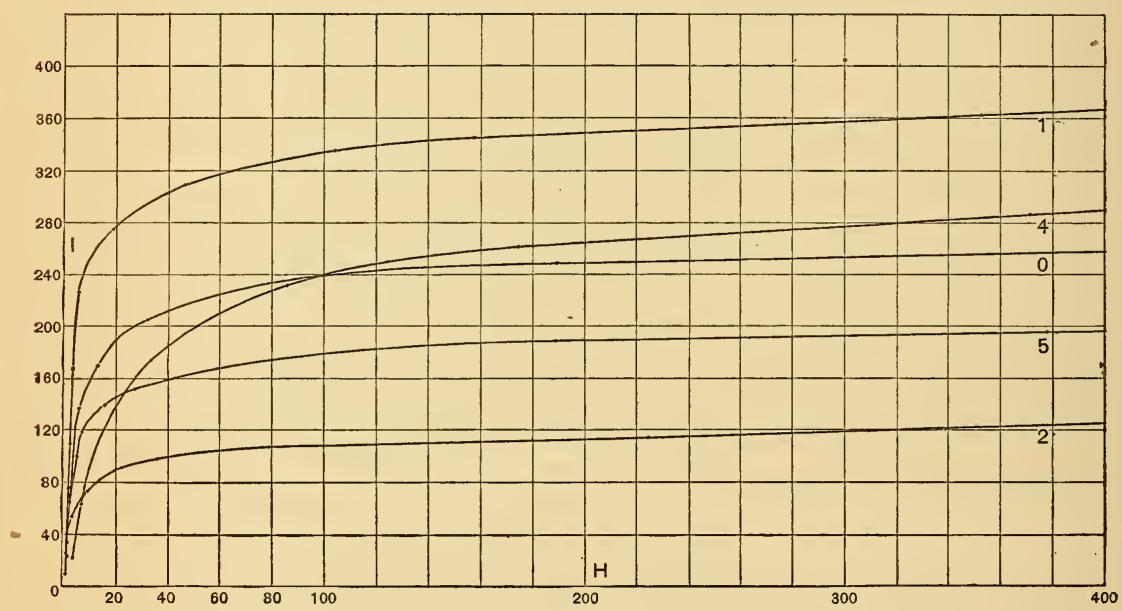

Fig. 1.-Curves for the Intensity of Magnetization.

to 4. The high induction in specimen I should be noticed as well as the peculiar curves for 4 showing the characteristic form of magnetically hard substances. No magnetic data are given for specimens 3 and 6 . These showed even in the strongest fields such small magnetization that they could be considered as practically nonmagnetic and unsuited for the comparisons desired. 
TABLE 1.

Alloy No. $0 ; N=0.045 ; n=548$.

\begin{tabular}{l|r|r|r|r}
\hline \multicolumn{1}{l|}{ Current } & H & I & B & $\mu$ \\
\cline { 2 - 4 } $0.022 \mathrm{amp}$. & 1.0 & 19.3 & 244 & 244 \\
0.059 & 2.7 & 72.0 & 907 & 336 \\
0.128 & 6.5 & 139.2 & 1756 & 270 \\
0.155 & 8.6 & 153.0 & 1921 & 224 \\
0.205 & 12.9 & 170.0 & 2150 & 167 \\
0.403 & 31.2 & 204.2 & 2594 & 83 \\
1.039 & 93.3 & 235.0 & 3043 & 33 \\
2.00 & 189 & 247.5 & 3294 & 17 \\
3.98 & 386 & 255.8 & 3600 & 9 \\
6.28 & 615 & 259.7 & 3875 & 6 \\
\hline
\end{tabular}

TABLE 2.

Alloy No. $1 ; N=0.121 ; n=440$.

\begin{tabular}{l|c|c|c|c}
\hline Current & H & I & B & $\mu$ \\
\cline { 2 - 3 } 0.0445 amp. & 0.8 & 23.6 & 298 & 372 \\
0.12 & 1.8 & 78.3 & 986.5 & 544 \\
0.16 & 2.4 & 109 & 1373 & 572 \\
0.24 & 3.8 & 167 & 2102 & 553 \\
0.351 & 7.9 & 225.5 & 2838 & 359 \\
0.52 & 19.1 & 272 & 3437 & 180 \\
0.859 & 48.5 & 309 & 3932 & 81 \\
1.424 & 102.0 & 334 & 4300 & 41 \\
2.00 & 157.9 & 348 & 4528 & 22 \\
3.96 & 352.3 & 361 & 4897 & 13 \\
5.78 & 534.0 & 364 & 5106 & 9 \\
6.98 & 653.7 & 366 & 5254 & 7 \\
\hline
\end{tabular}


The results show (as found by former observers) that of the lead free specimens I and 2 the former reaches a considerably higher magnetization, due to the larger percentage of the Manganesealuminium compound, while 3 with only $\mathrm{r}_{4} .66$ per cent of manganese is nonmagnetic. Both 4 and 5 , containing lead, lie in the main

TABLE 3.

Alloy No. 2; $N=0.155 ; n=394$.

\begin{tabular}{l|r|r|r|r}
\hline Current & H & I & B & $\mu$ \\
\cline { 1 - 2 } $0.022 \mathrm{amp}$. & 0.7 & 9.25 & 117 & 167 \\
0.0475 & 1.1 & 21.64 & 274 & 258 \\
0.0779 & 1.8 & 36.95 & 441 & 220 \\
0.0967 & 2.6 & 45.47 & 573 & 216 \\
0.1282 & 3.9 & 57.5 & 726 & 187 \\
0.133 & 4.1 & 59.5 & 752 & 183 \\
0.207 & 8.9 & 76.2 & 966 & 109 \\
0.354 & 21.5 & 89.8 & 1150 & 53 \\
0.501 & 35.2 & 96.4 & 1245 & 35 \\
0.940 & 78.2 & 105.5 & 1404 & 18 \\
2.4 & 222.8 & 114.3 & 1661 & 8 \\
4.49 & 421.1 & 119.5 & 1921 & 5 \\
\hline
\end{tabular}

TABLE 4.

Alloy No. $4 ; N=0.115 ; n=366$.

\begin{tabular}{l|c|c|c|c}
\hline Current & H & I & B & $\mu$ \\
\cline { 2 - 4 } $0.058 \mathrm{amp}$. & 2.7 & 23.6 & 299.4 & 111 \\
0.155 & 7.4 & 69.7 & 870 & 117 \\
0.257 & 13.0 & 108.5 & 1374 & 106 \\
0.500 & 30.22 & 172 & 2190 & 72 \\
1.12 & 85.4 & 231 & 2985 & 35 \\
2.04 & 174 & 260 & 3439 & 20 \\
4.03 & 371 & 278 & 3863 & 10 \\
6.23 & 590 & 284 & 4157 & 7 \\
9.15 & 882 & 286 & 4474 & 5 \\
\hline
\end{tabular}


between the other two, 4 showing for weak fields a smaller permeability than all the rest. The permeability of $\mathrm{O}$ is at first smaller than that of 2 or 5 , though in maximum induction it exceeds either of them.

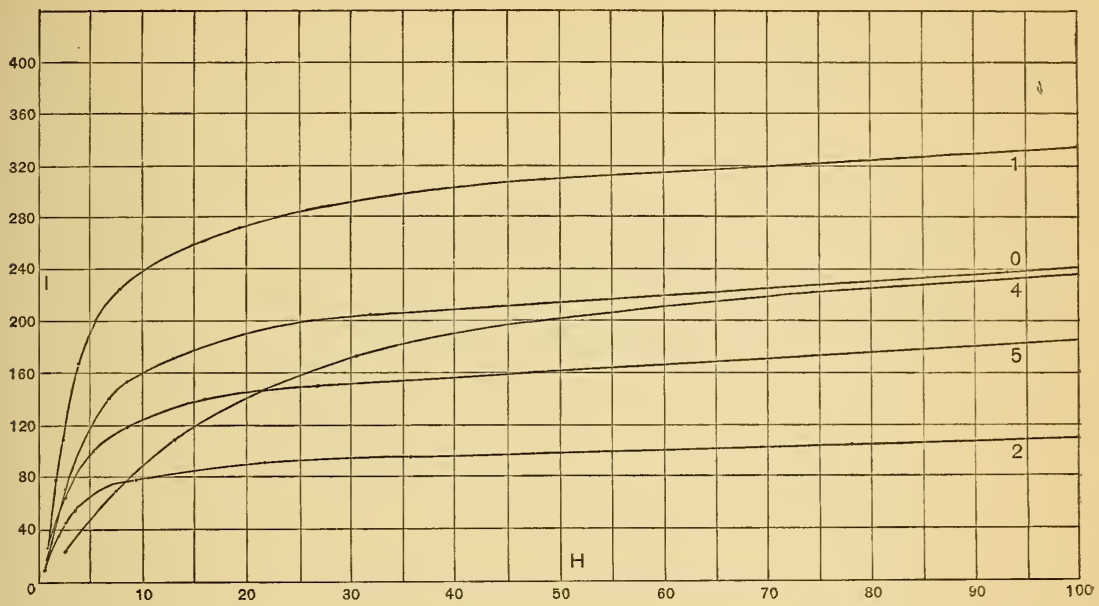

Fig. 2.-Curves for the Intensity of Magnetization.

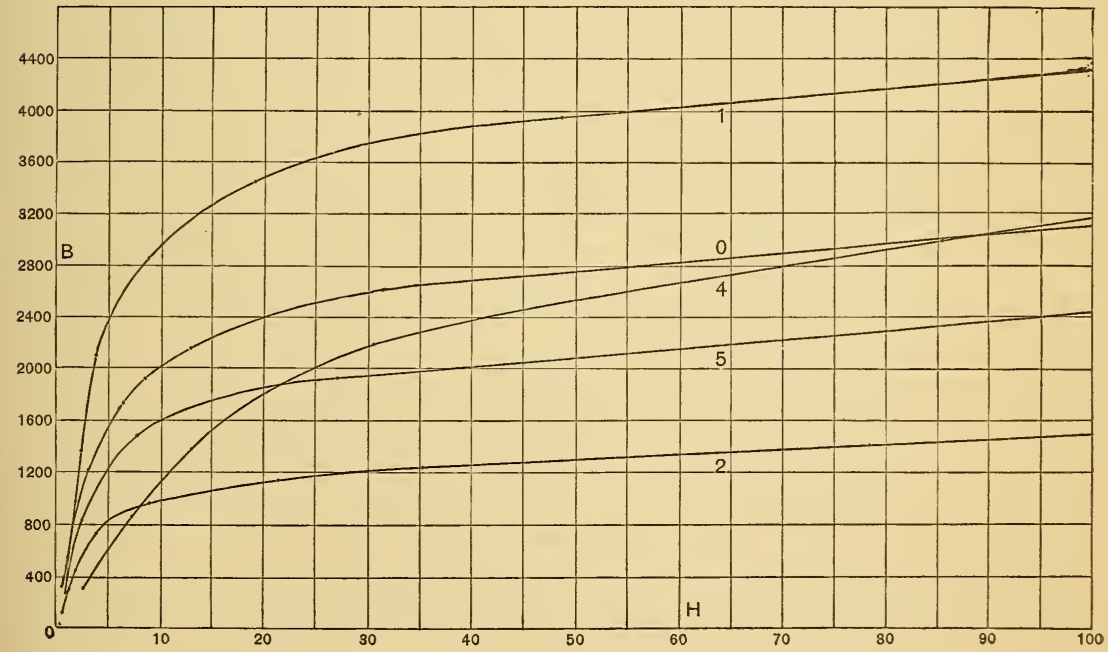

Fig. 3.-Curves of Magnetic Induction. 


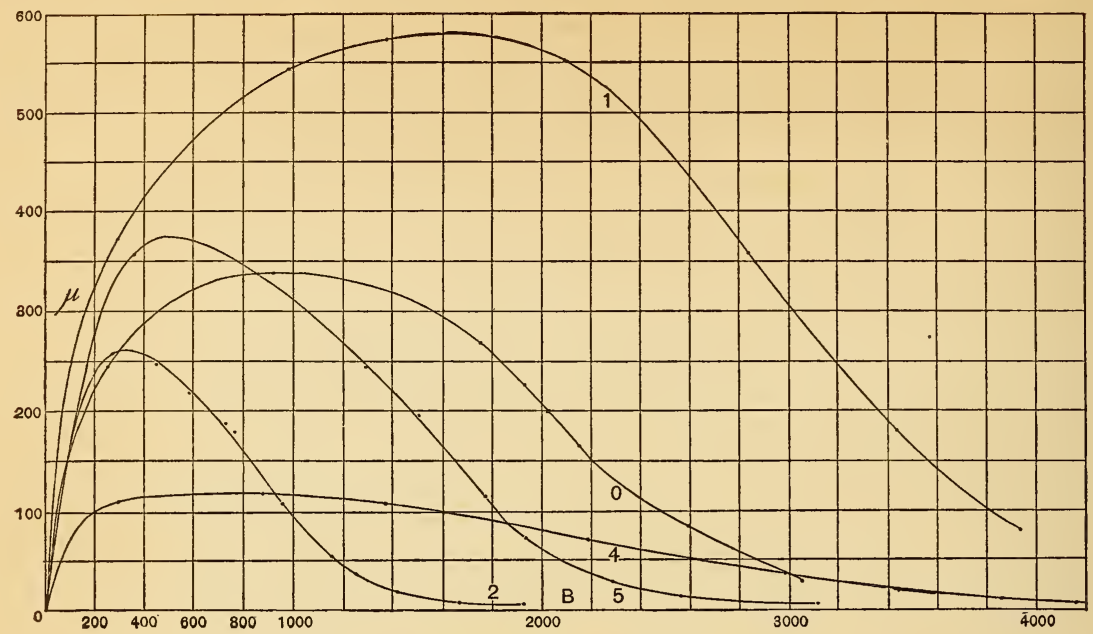

Fig. 4.-Curves of Permeability and Induction.

TABLE 5.

Alloy No. $5, N=0.1515, n=400$.

\begin{tabular}{l|l|l|l|l}
\hline Current & H & \multicolumn{1}{|c|}{ I } & B & $\mu$ \\
\cline { 2 - 4 } $0.058 \mathrm{amp}$. & 1.0 & 28.4 & 358 & 358 \\
0.128 & 2.5 & 67.1 & 845 & 338 \\
0.207 & 5.25 & 101.7 & 1281 & 244 \\
0.255 & 7.6 & 118.9 & 1499 & 197 \\
0.368 & 15.6 & 140 & 1775 & 112 \\
0.499 & 27 & 151.3 & 1928 & 71 \\
1.06 & 80 & 175.1 & 2280 & 28 \\
2.17 & 189.5 & 188 & 2550 & 13 \\
4.05 & 375.4 & 195.0 & 2825 & 8 \\
6.20 & 590 & 200.2 & 3108 & 6 \\
\hline
\end{tabular}

MAGNETOSTRICTION.

The apparatus used in measuring the magnetostriction was constructed as follows: The magnetizing coil $a$, already described under magnetic measurements, was fixed horizontally on a wooden base (see Fig. 5). The specimen of alloy $L$ was attached at both ends to brass tubes $M$, which were long enough to extend beyond the 
ends of the coil. Behind the coil a wooden block was screwed to the base, to the top of which was fastened a brass clamp $c$, in which was inserted the end of one of the brass tube extensions of the bar. The other brass extension projected from the front of the coil and was in contact with the apparatus for measuring the change in length. The brass extension piece in front was supported and pressed back against the block in the rear by means of a slotted flat

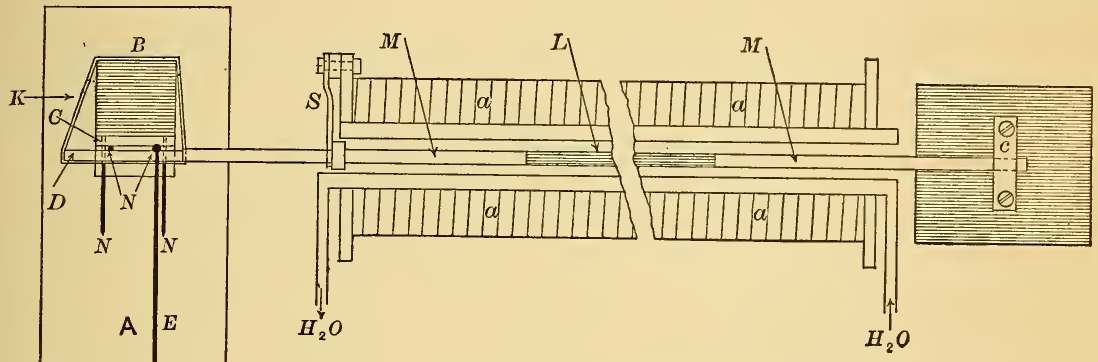

Fig. 5.-Plan of Magnetostriction Apparatus.

brass spring attached to the coil which pressed against a collar on the extension. The apparatus ${ }^{12}$ for measuring the change in length was constructed as follows: (See Fig. 6.) To a wooden base $A$ filled with lead a block $B$ was screwed, near the top of which a piece of mirror glass $C, 2.5 \mathrm{~cm}$ long and $2 \mathrm{~cm}$ wide, was cemented. Against this a second glass piece $D$, $3 \mathrm{~cm}$ long and $2 \mathrm{~cm}$ wide, was pressed by means of a rubber band $K$ passing around the block. Between the two glass plates were placed two vertical sewing needles $N, 0.34 \mathrm{~mm}$ in diameter, which rolled whenever the glass $D$ was moved forward or backward. The inside surfaces of the two glass plates were slightly ground with the intention of giving a better hold on the needles. The bottom of the moving plate also rested on needles rolling on a plate below. To the top of one of the vertical needles a very light glass arm $E$, ro. I cm long, was attached by a small brass cap. The end of the brass piece extending from the front of the specimen of alloy pressed against the movable glass plate; thus any expansion or contraction

12 This was the form of apparatus devised by Austin for measuring the magnetostriction of the alloys in the work already cited. 
caused the needle to roll and was indicated by the glass arm, magnified in the ratio of the length of the arm to the diameter of the needle. In order to further increase the magnification of the motion, we made use of Lord Kelvin's double suspension mirror method, i. e., a very light mirror $F$ was attached to the end of the glass arm, as shown in Fig. 6. One end of a loop of cocoon fiber was fastened to the end of the arm at $G$, and the other end to a fixed point $H$, the mirror being attached to the loop by a paper hook. The distance between the points of suspension of the threads was always about $1.6 \mathrm{~mm}$. The swings of the mirror were made nearly aperiodic by means of a small water damper.

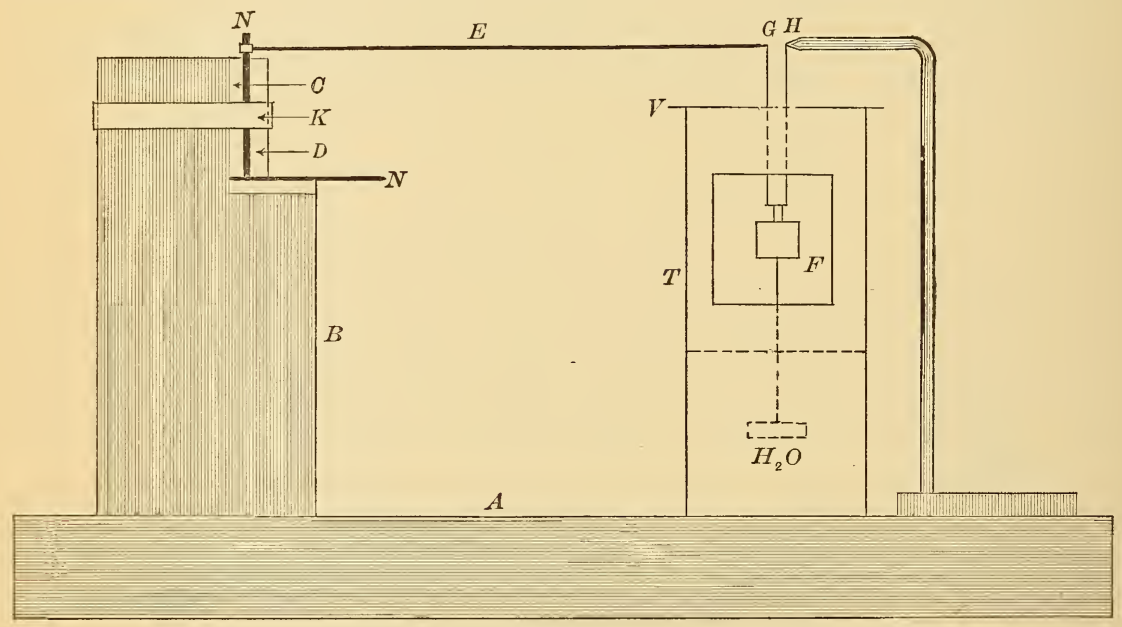

Fig. 6.-End View of Apparatus for Measuring Changes in Length.

The mirror and the threads were almost completely surrounded by a brass vessel $T$ with a glass front for observing the deflections of the mirror. The top of the vessel was covered with a piece of cardboard containing a narrow slit just wide enough to allow a free movement of the threads. Thus the mirror was effectively protected from disturbing air currents.

The sewing needles were the only portions of the apparatus which were made of iron. Preliminary experiments showed, however, that these were not disturbed when the coil was excited. Experiments were also made to detect any movement of the magnetized body as a whole, but none was observed, if the rods as in our experiments, were placed in the center of the coil. 
This apparatus is exceedingly well fitted for demonstration purposes, as with the exception of the coil it can be constructed in a rough but perfectly usable form in an hour. It is very little troubled by vibrations, if a water damper is used, and is simple in adjustment. By placing the points of suspension of the mirror nearer together it is quite possible to make the magnetic expansion of a $20 \mathrm{~cm}$ rod of iron produce a deflection of a spot of light on a screen 3 meters away, of more than a meter.

The principal constants of the expansion apparatus were as follows:

Length of glass arm $\mathrm{E}=$ IOI $\mathrm{mm}$

Distance from mirror to scale $l=\mathrm{I}, \mathrm{I} 35 \mathrm{~mm}$

Diameter of needle $\delta=0.35 \mathrm{~mm}$

Distance between suspension threads $d=$ about r. $6 \mathrm{~mm}$.

All of these quantities remained the same throughout the work with the exception of $d$, which was measured after each set of experiments by means of a filar micrometer, calibrated by comparison with a standard scale. The magnification ratio was:

$$
R=\frac{2 E l}{\delta d}=\frac{675000}{d}
$$

If we assume $d$ equal to $1.6 \mathrm{~mm}$, and that $0.2 \mathrm{~mm}$ is the smallest scale deflection which can be read with certainty, the smallest displacement recognizable would be $5 \times 10^{-7} \mathrm{~mm}$. The deflections were very consistent and were repeatedly checked with the different specimens. The expansion followed the formation of the magnetizing field instantaneously, and no after effect, either in expansion or in contraction was observed, even with the strongest fields. 
The results of the observations are shown in the following tables and curves.

TABLE VI.

Alloy No. o; $d=1.57 \mathrm{~mm}$.

\begin{tabular}{l|c|c|c|c}
\hline Current & $\mathrm{H}$ & $\mathrm{I}$ & Deflection & $\frac{\mathrm{dL}}{\mathrm{L}}$ \\
\hline $0.055 \mathrm{mp}$. & 2.5 & 70 & $2.0 \mathrm{~mm}$ & 0.27 \\
0.121 & 6.0 & 135 & 14.0 & 1.89 \\
0.195 & 11.6 & 167 & 23.0 & 3.11 \\
0.295 & 21.0 & 190 & 32.0 & 4.33 \\
0.425 & 33.2 & 206 & 41.0 & 5.55 \\
0.690 & 58.0 & 220 & 48.0 & 6.50 \\
1.145 & 104.0 & 237 & 62.0 & 8.40 \\
2.50 & 240 & 250 & 67.0 & 9.07 \\
5.80 & 572 & 259 & 82.0 & 11.10 \\
8.60 & 843 & 261 & 83.0 & 11.23 \\
\hline
\end{tabular}

TABLE VII.

Alloy No. $1 ; d=1.63 \mathrm{~mm}$.

\begin{tabular}{l|r|r|c|c}
\hline Current & $\mathrm{H}$ & $\mathrm{I}$ & Defiection & $\frac{\mathrm{dL}}{\mathrm{L}} \mathrm{ro}^{7}$ \\
\cline { 2 - 4 } $0.061 \mathrm{amp}$. & 1.0 & 32 & $0.2 \mathrm{~mm}$ & 0.04 \\
0.163 & 2.6 & 116 & 5.8 & 1.03 \\
0.340 & 7.3 & 220 & 18.3 & 3.23 \\
0.522 & 19.3 & 273 & 38.8 & 6.90 \\
1.03 & 64.0 & 316 & 61.8 & 10.95 \\
1.65 & 124.0 & 338 & 75.5 & 13.45 \\
2.51 & 209.0 & 348 & 85.5 & 15.20 \\
6.15 & 568.0 & 365 & 97.3 & 17.35 \\
\hline
\end{tabular}

As may be seen from the tables and curves, the expansion curves are quite similar in their general form to those for the intensity of magnetization with the difference, characteristic for all the alloys, that the expansion is very small for weak fields; it is, in fact, hardly appreciable for fields smaller than one gauss. The more pronounced the magnetic properties the larger the relative expansion, reaching 
TABLE VIII.

Alloy No. 2; $d=1.54 \mathrm{~mm}$.

\begin{tabular}{l|r|c|c|c}
\hline Current & H & I & Deflection & $\frac{\mathrm{dL}}{\mathrm{L}} \mathrm{ro}^{7}$ \\
\cline { 1 - 3 } $0.057 \mathrm{amp}$. & 1.4 & 25 & $0.5 \mathrm{~mm}$ & 0.08 \\
0.152 & 5.1 & 66 & 2.5 & 0.47 \\
0.305 & 17.0 & 86 & 7.7 & 1.46 \\
0.490 & 34.2 & 94 & 8.3 & 1.57 \\
0.912 & 75.0 & 105 & 11.0 & 2.06 \\
1.80 & 164.0 & 112 & 13.5 & 2.54 \\
2.25 & 207.0 & 114 & 14.0 & 2.64 \\
5.60 & 527.0 & 120 & 15.0 & 2.82 \\
\hline
\end{tabular}

TABLE IX.

Alloy No. 4; $d=1.57 \mathrm{~mm}$.

\begin{tabular}{l|r|r|r|r}
\hline Current & $\mathrm{H}$ & $\mathrm{I}$ & Deflection & $\frac{\mathrm{dL}}{\mathrm{L}} \mathrm{IO}{ }^{\top}$ \\
\cline { 3 - 4 } $0.057 \mathrm{amp}$. & 2.7 & 23 & $0.5 \mathrm{~mm}$ & 0.08 \\
0.150 & 7.0 & 65 & 6.3 & 0.96 \\
0.300 & 15.7 & 122 & 17.0 & 2.70 \\
0.485 & 29.3 & 169 & 30.0 & 4.84 \\
0.895 & 65.0 & 220 & 52.5 & 8.25 \\
1.25 & 98.0 & 238 & 65.0 & 10.22 \\
1.60 & 130.0 & 248 & 71.0 & 11.15 \\
2.20 & 188.0 & 262 & 73.8 & 11.63 \\
5.40 & 510.0 & 282 & 82.5 & 12.98 \\
\hline
\end{tabular}

in alloy No. I one-half the maximum found for soft iron. A contraction in stronger fields, as high as I, ooo, has not been observed.

A direct comparison between magnetostriction and the intensity of magnetization is given by the curves of Fig. 8 . It is seen that the expansion is not proportional to the magnetization, but increases more rapidly. It is interesting to note that the expansion is relatively larger the softer the material. As stated above, No. I is the hardest, 2 and 4 follow and are about equally hard, while 5 is relatively the softest. The exceptional position of 4 has in this 
TABLE X.

Alloy No. 5; $d=1.63 \mathrm{~mm}$.

\begin{tabular}{l|r|r|r|r}
\hline Current & H & I & Deflection & $\frac{\mathrm{dL}}{\mathrm{L} \text { I07 }}$ \\
\cline { 1 - 2 } $0.055 \mathrm{amp}$. & 1.0 & 29 & $0.75 \mathrm{~mm}$ & 0.14 \\
0.148 & 3.2 & 74 & 6.5 & 1.26 \\
0.289 & 9.5 & 123 & 17.8 & 3.46 \\
0.472 & 24.9 & 149 & 26.0 & 5.05 \\
0.872 & 66.0 & 169 & 36.5 & 7.10 \\
1.40 & 113.0 & 180 & 41.5 & 8.07 \\
2.14 & 184.0 & 187 & 47.0 & 9.13 \\
5.22 & 494.0 & 198 & 52.0 & 10.10 \\
\hline
\end{tabular}

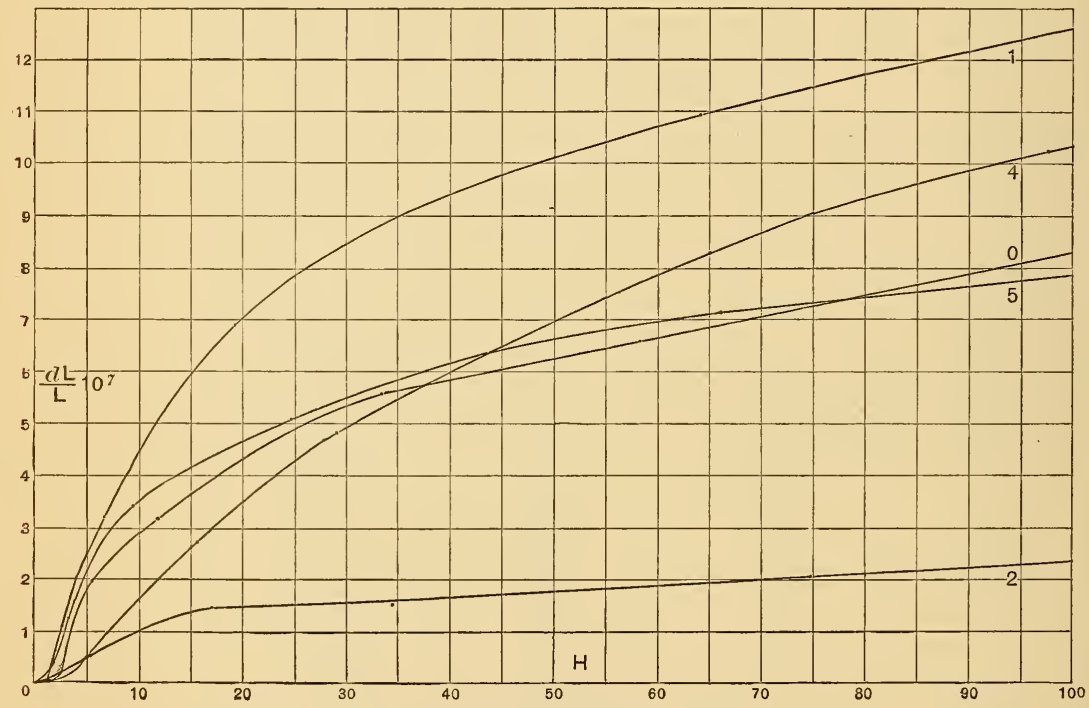

Fig. 7.-Curves for Magnetostriction.

case disappeared. It seems to be a fair conclusion to assume that the harder the alloy, the higher Young's modulus; but, as already mentioned, it was impossible to determine the latter, due to the mechanical imperfections of the rods. 


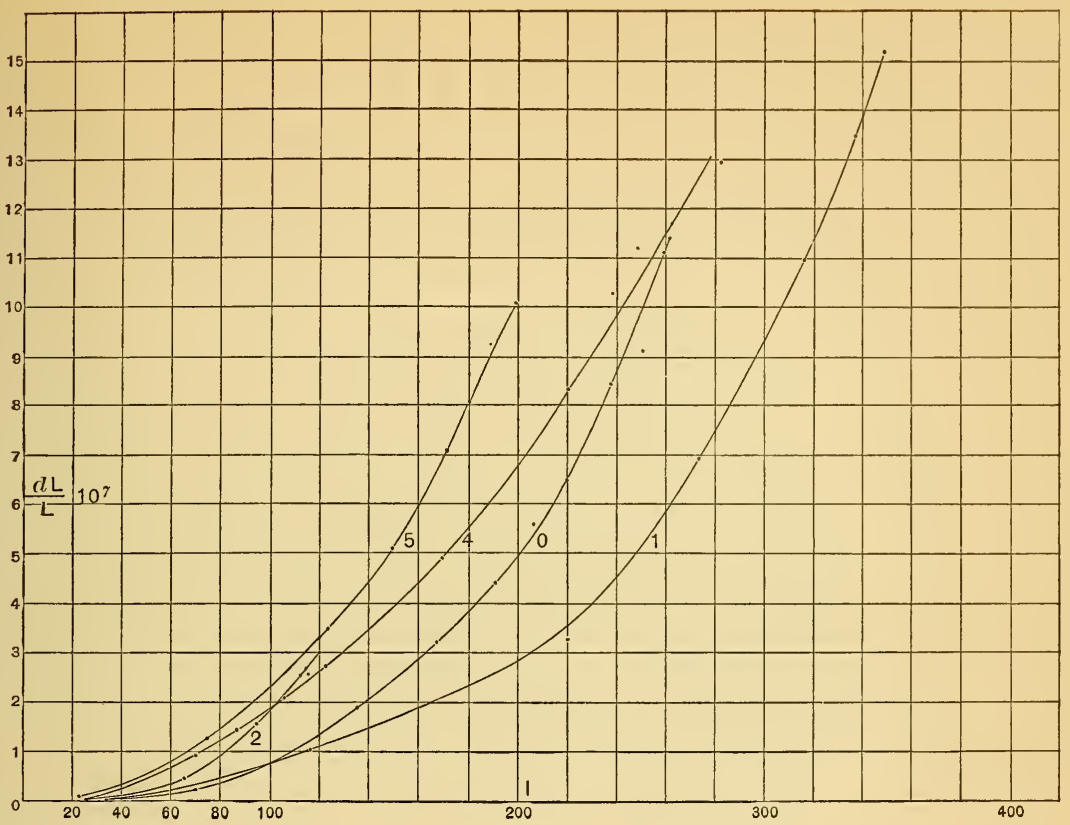

Fig. 8.-Magnetostriction as a Function of I.

THERIMOELECTRIC POWER.

Bidwell's observation that the change of the thermoelectromotive force of iron and nickel is proportional to the magnetic expansion, corrected for the mechanical stress, led us to try some similar experiments with these Heusler alloys. Around their ends thin copper wires were wound tightly. They were then placed in the center of a glass tube just fitting inside the magnetizing coil (Fig. 9). Rub-

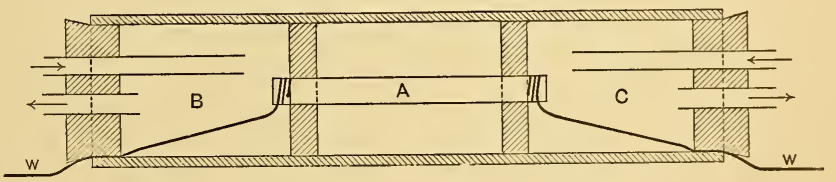

Fig. 9.-Apparatus for Thermoelectric Measurements.

ber stoppers were placed on the rods near the thermojunctions and the glass tube was closed at both ends by stoppers, through which two smaller tubes passed for the circulation of warm and cold water, respectively, in the chambers $\mathrm{B}$ and $\mathrm{C}$. The thermoelectromotive 
force produced by the difference of temperature was balanced by means of a potentiometer. A change in the emf. of one microvolt gave a galvanometer deflection of $2 \mathrm{~mm}$. At first only moderate differences of temperature $\left(50^{\circ}\right)$ were used, but when not the slightest effect was observed on magnetizing the rods, we finally sent steam through the heating chamber, while ice-cold water flowed through the other. In this case also, though the thermoelectromotive force amounts to several millivolts we were unable to detect any change as large as 0.5 microvolt for any of the alloys, even in fields as large as I,OoO gausses. Bidwell found for iron and a temperature difference of about $85^{\circ}$ a change as large as 15 microvolts in a field of 200 gausses in the case of nickel, and 25 microvolts. In connection with this, we may add that C. E. Mendenhall has informed us by letter that he was unable to find Kerr's phenomenon in a piece of Heusler alloy. We may therefore draw the interesting conclusion that in these alloys certain properties seem to be absent which have always been thought to be closely connected with magnetic substances. 